\title{
A Revista ORPHEU e o Brasil
}

Arnaldo Saraival

\begin{abstract}
This article focuses on the origin of Orpheu Magazine, as a Luso-Brazilian project, with portuguese director Luis Montalvor and the Brasilian director Ronald de Carvalho . It rescues the Brazilian contribution of the poets Ronald de Carvalho and Eduardo Guimarães and highlights the Orpheu 's reception in Brazil, where it was launched its first seed.

Keywords: Orpheu; Luiz de Montalvor; Ronald de Carvalho; Eduardo Guimarães; aesthetic reception.

Resumo: Este artigo focaliza a revista Orpheu, em sua origem, como projeto luso-brasileiro, tendo na direção por Portugal Luís de Montalvor e, pelo Brasil, Ronald de Carvalho. Resgata a contribuição brasileira dos poetas Ronald de Carvalho e Eduardo Guimarães e destaca a recepção de Orpheu no Brasil, onde foi lançada sua primeira semente.
\end{abstract}

Palavras-Chave: Orpheu; Luiz de Montalvor; Ronald de Carvalho; Eduardo Guimarães; recepção estética.

Introdução

Orpheu, como muitas revistas portuguesas anteriores ou posteriores, era um projeto luso-brasileiro, até para melhor garantir a sobrevivência. No frontispício do primeiro número aparecia o subtítulo "Portugal e Brasil" e era destacada a "Direção" para "Portugal" e para o "Brasil", sendo até dados os endereços pessoais dos diretores Luís de Montalvor ("17, Caminho do Forno do Tijolo — LISBOA") e Ronald de Carvalho ("104, Rua Humaytá - RIO DE JANEIRO”); os dois tinham idealizado em conversas de Copacabana, em 1914, uma revista dos novos de Portugal e do Brasil; Ronald manifestou-se empenhado na angariação de assinantes brasileiros da revista e publicou sete poemas no seu primeiro número, que previa vendas avulsas e assinaturas (quatro números) não só em "Portugal, Espanha e Colónias portuguesas", ao preço de "30 centavos" e "1 escudo", mas também no "Brasil", ao preço de " $1 \$ 500$ réis fracos" e "5\$000 réis (moeda fraca)"; e na indicação de "obras dos colaboradores" do primeiro número não era esquecida Luz Gloriosa, de Ronald de Carvalho. Curiosamente, até a "depositária" da revista era a "Livraria Brasileira" da Rua do Ouro.

\section{O nome do Orpheu}

A ideia de se revelarem ou firmarem por meio de uma revista, meio de comunicação intermediário entre o peso do livro e a leveza do jornal ou do folheto, que nos finais do sec.XIX ganhara o gosto de velhos e novos leitores, às vezes atraídos pelas ilustrações, muitos jovens autores portugueses, como outros estrangeiros, a tiveram; a ideia de uma revista como seria o Orpheu começou a definir-se quando Pessoa se desligou da Águia, e

1 Doutor em Filologia Românica pela Universidade do Porto - PT 
foi sendo incubada quando Pessoa e Sá-Carneiro projetaram as revistas Lusitânia - de que em fevereiro de 1913 já havia um "plano completo" - e Europa - para que em 1914 ele já escrevera parágrafos de um manifesto. Projetos que rejeitaram desde logo por terem os limites que os nomes Lusitânia e Europa insinuavam. Mas o nome da revista que à partida conceberam como cosmopolita veio do Brasil, o que parece simbolicamente relevante, trazido por Luís de Montalvor, que desde os fins de 1912 aos de 1914 conviveu no Rio de Janeiro com jovens poetas que também sentiam a necessidade do mesmo tipo de revista, como pode deduzir-se de uma nota da revista carioca Fon-Fon! de 26 de abril de 1913 ("Todos estes belos espíritos que surgem /.../precisam iniciar um movimento em que o seu destaque seja decisivo e benéfico") e da evocação que Montalvor fez do seu convívio carioca com Ronald de Carvalho :"Data dessa época a gestação, o plano, in mente, da fundação de uma revista eclética, repositório vivo, documentário incisivo dos vários modos de ser, dos anseios, das curiosidades estéticas da gente nova"2.

Ronald de Carvalho permite alguma dúvida sobre a responsabilidade da escolha do nome da revista: "Sabes que esse é o meu, antes, o nosso Orfeu, cuja primeira semente floriu ao pé das ondas de Copacabana"- escreveu ele em carta a Montalvor de Março de 1915; e em carta de Abril de 1915 também falou do "nosso Orfeu".

Mas Montalvor pareceu claro a garantir que foi ele o padrinho: "revista esta que mais tarde eu batizei com o título de Orpheu" ${ }^{3}$.Fernando Pessoa confirmou a importância que Montalvor teve para o nome e para a para o arranque da revista: "Em princípio de fevereiro de 1915 (se me não engano) regressou do Brasil Luís de Montalvor, e uma vez, em fevereiro (creio), encontrando-se no Montanha comigo e com o Sá-Carneiro, lembrou a ideia de se fazer uma revista brasileiros jovens, e a ideia do próprio título da revista - Orpheu"4 .

A verdade é que o documento em que aparece escrito pela primeira vez o título de Orpheu não se deve a Montalvor nem a Ronald de Carvalho, mas a Fernando Pessoa, que em 19 de fevereiro de 1915 anunciou a Armando Côrtes Rodrigues: "Vai entrar imediatamente no prelo a nossa revista, Orpheu" ${ }^{\text {. }}$

\subsection{A grafia do nome ORPHEU}

Fernando Pessoa escreveu Orpheu, com ph. Mas em tempos que já eram, imagine-se, de acordos e desacordos ortográficos, não faltava quem escrevesse com $\mathrm{f}$, mesmo entre os colaboradores da revista. Ronald de Carvalho, por exemplo, usou sempre essa grafia nas cartas a Montalvor. Recorde-se aliás o que Almada Negreiros escreveu no Diário de Lisboa de 8 de Março de 1935: que no Orpheu até a ortografia era a de cada autor.

Pensando que o nome da revista veio do Brasil não é difícil entender a preferência pela grafia com $p h$ - porque toda a imprensa do Rio a usava então, quer na referência ao mito, quer na referência a espetáculos de música ou dança, quer em nomes individuais. Fica assim algo desfavorecida a hipótese da sugestão arcaizante (somada à do mito grego) que alguns viram nessa grafia, ou a de que o padrinho ou os padrinhos dela tinham imitado os da revista coimbrã de 1912, Dionysos, com y grego.

2 Modernismo Brasileiro e Modernismo Português, Campinas, Unicamp, 2004, pp.594-595.

3 Id., p.595.

4 Id., p.100.

5 Fernando Pessoa, Correspondência 1905-1922, ed. de Manuela Parreira da Silva, Lisboa, Assírio \& Alvim, 1999, p. 148. 


\section{O tempo de ORPHEU}

De acordo com o testemunho de Carlos Maul, que na sua casa de Copacabana acolheu Montalvor, este "Tinha em mente realizar um poema intitulado «Orfeu», de revivescência do mito helénico" $\left({ }^{6}\right)$, que nunca concluiria.

É provável que o nome, o tema ou motivo de Orfeu já o tivesse levado de Portugal, quem sabe se trabalhado ou conjeturado com a ajuda de ventos culturais que sopravam de França e de que Montalvor muito gostava, como aliás inúmeros seus contemporâneos fora de França. Esses ventos não eram só literários (Orfeu foi celebrado por inúmeros autores franceses, como Nerval, Lecomte de Lisle, Valéry, Apollinaire...), porque podiam ser também visuais (Gustave Moreau, Ingres, Raoul Dufy....) e musicais, mesmo que com origens fora de França (Gluck, Liszt, Offenbach...), e podiam ser religiosos ou esotéricos, soprados até por seitas órficas, que em 1909 terão determinado o título da famosa obra de Salomon Reinach, Orpheus- Histoire Générale des Religions.

Não por acaso, encontramos o nome de Orfeu em obras de amigos cariocas de Montalvor, alguns dos quais foram convidados para colaborar no Orpheu ; Ernani Rosas, que por sinal dedicou aos que chamou " irmãos de Salomé” - Montalvor, Mário de Sá-Carneiro e a Ronald de Carvalho - o seu livro Poema do Ópio (1918), incluiu neste livro o soneto datado de 16 de Dezembro de 1913 que começa assim:'Trago de Hamlet a dúvida sombria, / de Orfeu o canto e a lira melodiosa"; Eduardo Guimaraens publicou na revista Fon-Fon de 23 de Dezembro de 1915 um soneto intitulado "Orpheu"; e Homero Prates publicou em 1923 o livro que intitulou Orfeu. Quatro anos antes, o poeta Olavo Bilac, que sem dúvida marcou o poeta da Mensagem, deixara no livro A Tarde (1919) o célebre poema "A morte de Orfeu":

Luz da Grécia, pontífice de Apolo, Orfeu, despedaçada a lira ao colo, A carne rota ensanguentando o solo, Tombou...E abriu-se em músicas o chão...

Curiosamente, no discurso com que em 1916 o saudou numa homenagem em Lisboa, Guerra Junqueiro falara nos "novos Orfeus" do Brasil. Que não seriam certamente o "Orpheu do silogismo" que alguém quis ver mais ou menos por essa altura no orador, jurista e polemista Rui Barbosa, ou o "Orpheu do seringal” que o poeta Humberto de Campos quis ver no irapuru:

Dizem que o irapuru, quando desata

A voz - Orpheu do seringal tranquilo -

O passaredo, rápido, a segui-lo

Em derredor agrupa-se na mata ${ }^{7}$.

Mas a imprensa carioca da década 10-20 publicou outros poemas inspirados em Orfeu, como os de Ludgero Alves Cabral (O Malho) e de Francisco Ricardo (O País), antecessores de outros textos bem mais memoráveis, como A Invenção de Orfeu, de Jorge de Lima, o

6 O Rio da Bela Época, Rio de Janeiro, Livraria S. José, 1967, p.165.

7 Do livro Poeira, de 1911. 
Orfeu Negro, de Vinicius de Moraes, ou o famoso "Exergo" de Murilo Mendes ("Orfeu Orftu Orfele / Orfnós/ Orfvós Orfeles" - sem esquecer poetas mais recentes como Adriano Espínola, Geraldo Carneiro e Rodrigo Petronio, estudados por António Donizeti Pires ${ }^{9}$.

$\mathrm{Na}$ imprensa carioca também comparecia com alguma frequência o nome "Orpheu", fosse a propósito de um concerto em que por exemplo se tocou ou cantou Gluck, ou de algum ballet, protagonizado por exemplo por Isadora Duncan, ou de alguma lenda, oferecida em folhetins, ou da inauguração de uma loja teosófica (na Rua do Catete, 287, em 30 de Setembro de 1919), ou fosse até a propósito de alguma pessoa, como "o sr. e a sra Orpheu" (num jornal de 11 de Abril de 1915), ou como os senhores Orpheu da Silva Rodrigues, Orpheu Frederico Cunha e Eugénio Orpheu, este, ao que parece, autor de uma serenata que, dizia o jornal, só pelo nome já garantia a boa execução. (Oh, também encontrei no jornal carioca O País a de 1 de Janeiro de 1912 a referência a um aluno do colégio Pedro II chamado Fernando Pessoa - que obviamente ninguém confundiria com o Fernando Pessoa que assinava várias traduções da obra em 24 volumes que nesse ano ou no início do seguinte se vendeu no Brasil com o título Biblioteca Internacional de Obras Célebres).

Diga-se a propósito, para surpresa ou espanto geral, que os quatro diretores de Orpheu - Montalvor, Ronald, Pessoa, Sá-Carneiro - já em 1914 marcavam presença na cultura brasileira, e tinham estabelecido relações entre si.

\title{
3 A recepção do ORPHEU no Brasil
}

Projetada no Brasil, projetada como revista para Portugal e para o Brasil, a revista Orpheu só se valeu da colaboração de 2 brasileiros, Ronald e Eduardo Guimaraens, numa desproporção enorme; o diretor brasileiro do $1^{\circ}$ número foi afastado e substituído, apressadamente, e talvez sem nenhuma explicação direta dos novos diretores, que na explicação pública nem se preocuparam em referir o seu nome, como se só devessem uma explicação ao outro diretor substituído; veja-se o que escreveram:

\begin{abstract}
Várias razões, tanto de ordem administrativa, como referemtes à assunção de responsabilidades literárias perante o público, levaram o comité redactorial de ORPHEU a achar preferível que a direção da revista fosse assumida pelos actuais diretores, não envolvendo tal determinação a mínima discordância com o nosso camarada Luís de Montalvor, cuja colaboração, aliás, ilustra o presente número.
\end{abstract}

Tudo leva a crer que nem foi enviada para assinantes brasileiros que Ronald de Carvalho supostamente angariara, a revista que, inesperadamente, se esgotou em Portugal em duas semanas. Porque nunca encontrei notícia ou rasto de algum exemplar que tivesse pertencido a Ronald ou a outro escritor brasileiro. Até hoje só me foi dado saber de um exemplar que chegou a uma revista carioca, que deu o Orpheu como uma "publicação que honra sobremaneira os centros intelectuais portugueses e brasileiros," por isso lhe desejando "o mais brilhante futuro", e que até louvou o seu papel de "superior qualidade", garantindo que podia "mesmo sofrer o confronto" com duas das mais cotadas publicações parisienses.

Supunha eu que esta era a única referencia da imprensa brasileira de 1915 ao Orpheu, Mas descobri recentemente que outra publicação carioca, o Correio da Manhã, publicou 
em 15 de outubro de 1915 a longa crónica intitulada "Novo Orpheu"- que no entanto foi enviada de Lisboa ... e pelo português Sousa Costa, nascido em 1879, bacharel de direito pela Universidade de Coimbra, escritor de várias espécies textuais, e camilianista . Nessa crónica, o autor começa por dizer que não sabe "se já chegou ao Brasil o eco da música do novo Orpheu - o verdadeiro “, pois o outro, o da Grécia, "não está averiguado se existiu"; e garante que "para a história, para o mais luzido dos seus altares, entrou já, e não conta senão três meses, o Orpheu actual". Por este início, não seria difícil adivinhar que estávamos perante mais um dos muitos textos que pretenderam atacar ou gozar com o Orpheu. E o que vinha a seguir não fugia ao modelo instaurado pelo diário lisboeta $A$ Capital, que logo em 30 de Março de 1915 - quer dizer, 4 ou 5 dias depois da publicação da revista - em duas colunas da primeira página, denunciava a"paranoia" dos colaboradores de Orpheu, que pertenceriam a "uma categoria de indivíduos que a ciência definiu e classificou dentro dos manicómios". Sousa Costa dispensou os comentários depreciativos: "devo, antes, para sua glória /do Orpheu/ e vossa satisfação, deixar que ele fale, e vos infiltre no cérebro a atividade clara da sua música". Assim, passou a transcrever passagens de colaborações do $\mathrm{n}^{\circ} 2$ de Orpheu - da autoria de Ângelo de Lima, Mário de Sá-Carneiro e Álvaro de Campos -, gracejando também sobre a colaboração plástica de Santa Rita Pintor, para no fim insinuar, numa historieta, que, como dissera A Capital, se tratava de "artistas de Rilhafoles".

O leitores brasileiros do Correio da Manhã devem ter ficado esclarecidos sobre a importância do Orpheu - e gratos por tão "engraçada" prosa que lhes chegara de Portugal.

\section{As colaborações brasileiras do ORPHEU}

Ronald de Carvalho só colaborou no primeiro Orpheu, com 5 sonetos e mais dois poemas em quadras; no segundo compareceu Eduardo Guimaraens com três poemas, um dos quais — "Sob os teus olhos sem lágrimas" — saíra na revista carioca Fon-fon! quatro meses antes da sua publicação na revista portuguesa; e nos projetos do n. ${ }^{\circ} 3$ já não entrou nenhuma colaboração de brasileiros.

Mas por uma carta de Ronald a Montalvor, que publiquei no livro Modernismo Brasileiro e Modernismo Português, sabemos que foram previstos outros colaboradores brasileiros, mais ou menos coetâneos dos portugueses: Álvaro Moreira, Homero Prates, Alcides Maia, Graça Aranha - que, como Ronald, ganharia grande relevância em tempos modernistas do Brasil - e Ernani Rosas. No minucioso e erudito Panorama do Movimento Simbolista Brasileiro (1973) diz Andrade Muricy que este último colaborara no Orpheu. Quando lhe perguntei onde ou como obtivera essa equivocada informação ele respondeu-me que a obtivera da boca do próprio Ernani Rosas, a quem é certo que em março de 1915 Luís de Montalvor dirigiu, por intermédio de Ronald de Carvalho, uma carta a pedir colaboração para a revista, "este sonho enorme que vamos realizar".

Montalvor tinha-se tornado seu amigo quando viveu no Rio de Janeiro, dos fins de 1912 aos de 1914, altura em que também se familiarizou com outros jovens escritores, como Eduardo Guimaraens, Ronald de Carvalho e Carlos Maul, e foi referenciado pela imprensa carioca. O que é espantoso é que, como já referi, os dois outros escritores portugueses mais responsáveis pelo Orpheu também então apareceram na imprensa carioca. Mário de Sá-Carneiro teve textos seus publicados em 1913 na carioca Gazeta de Notícias e em 1914 nas revistas Fon-fon! e Careta, recebendo elogios públicos de Carlos Maul e de Ronald de Carvalho, e influenciando claramente, entre outros, Ernani Rosas, por sinal 
autor de um soneto datado de 16 de dezembro de 1913 em que fala de Orfeu, e esquecido poeta justamente estimado pelo concretista Augusto de Campos. E o nome de Pessoa, que alguns brasileiros devem ter lido logo em 1912 na Águia (que tinha muitos leitores no Brasil), surgiu pela primeira vez na imprensa brasileira (Gazeta de Notícias) em 15 de junho de 1913, graças a Mário de Sá-Carneiro, que lhe dedicou "O homem dos sonhos". Só que por essa altura, sem que ninguém o assinalasse, ele também comparecia, assinando traduções, em volumes da Biblioteca Internacional de Obras Célebres, que entraram em muitas casas brasileiras - incluindo a de Carlos Drummond de Andrade, então com onze, doze anos de idade, que os guardaria no seu escritório carioca e até lhes dedicaria um poema. Assim, mais estranho parece que a publicação de Orpheu passasse despercebida no Brasil, em contraste com o que se passou em Portugal.

Apesar de não ser tipicamente modernista, não se pode dizer que carecia ou carece de interesse a colaboração dos dois brasileiros de Orpheu. Os poemas de Ronald de Carvalho antecipam o penumbrismo que ele próprio teorizou em 1921, antes de dar o salto para o verso livre ou para os jogos rítmicos e subtis de Epigramas irónicos e sentimentais e de Toda a América: neles deparamos com atmosferas crepusculares, sombrias ou lunares e com um sentimentalismo romântico e decadentista em que todavia assomam sugestões modernistas (a alma dividida, o sujeito que se estranha, a perda da razão), assim como deparamos com um vigiado gosto de metáforas simbolistas e com uma enunciação elegante e depurada. Os poemas de Eduardo Guimaraens, bem esculpidos ou construídos, denunciam o seu treino de tradutor de poesia, ou a sua boa leitura de bons poetas portugueses como Cesário Verde e franceses como Mallarmé, e afastam-se de estereótipos parnasianos ou simbolistas pela gravidade dos motivos e por delicadas transições entre o subjetivo e o objetivo.

\section{Considerações finais}

O Orpheu não pôde contribuir muito para o estreitamento das inteligências portuguesas e brasileiras, como Pessoa e os seus companheiros desejavam. O movimento modernista brasileiro, que teve a sua epifania em São Paulo durante a Semana de Arte Moderna de Fevereiro de 1922, seria certamente ainda mais fecundo se alguns dos que nele militaram se tivessem apercebido de que Portugal não estava a pedir nenhuma "câmara funerária" , como supôs Graça Aranha, nem era "um povo que gerou Os Lusíadas e morreu”, como supôs o próprio Drummond numa boutade de 1924. Mas o facto de ter sido no Brasil que foi lançada a "primeira semente" do Orpheu, como disse Ronald numa carta enviada a Montalvor em março de 1915, ou o facto de nele terem colaborado dois brasileiros - e nenhuns outros estrangeiros - transporta certamente um alto valor simbólico, tanto mais que, como em Portugal, já são hoje numerosos no Brasil os estudos sobre a revista "extinta e inextinguível" (Pessoa), ou sobre o movimento que ela produziu, e ainda não parou.

\section{Referências}

MAUL, Carlos. O Rio da Bela Época. Rio de Janeiro: Livraria S. José, 1967, p.165. PESSOA, Fernando. Correspondência 1905-1922, ed. de Manuela Parreira da Silva, Lisboa: Assírio \& Alvim, 1999.

SARAIVA, Arnaldo. Modernismo Brasileiro e Modernismo Português. Campinas: Unicamp, 2004. 